\title{
A non-spectroscopic optical biosensor for the detection of pathogenic Salmonella Typhimurium based on a stem-loop DNA probe and retro-reflective signaling
}

\author{
Dong Woo Kim, Hyeong Jin Chun, Jae-Ho Kim, Hyunjin Yoon and Hyun C. Yoon ${ }^{*}$
}

\begin{abstract}
The detection of foodborne pathogenic microorganisms is an essential issue in molecular diagnostics. Fluorescencebased assays have been widely utilized in molecular diagnostics because of their ability to detect and measure low analyte concentrations. However, conventional fluorescence-based assays require sophisticated optics systems, such as a specific light source and light filter. To overcome these limitations, we developed an optical sensing system using a retroreflective Janus microparticle (RJP) as a signaling probe. Compared to fluorescent dyes, RJPs have the advantage of not requiring complicated optic systems because they can be observed using visible light without a filter. To confirm that RJPs can be used as a probe for molecular diagnostics, Salmonella was detected using a biotinylated stem-loop DNA probe to capture the target gene DNA and a streptavidin-conjugated RJP (SA-RJP) as the detection molecule. When the target gene DNA was present at the sensing surface where the stem-loop DNA probe was immobilized, the biotinylated stem-loop DNA probe was stretched, exposing biotin, which can react with SA-RJP. Since the amount of exposed biotin increased according to the concentration of the applied target gene DNA, the number of observed RJPs on the sensing surface increased with the concentration of the target gene DNA. Consequently, the concentration of Salmonella could be quantitated by counting the number of observed RJPs. Using this system, Salmonella at concentrations ranging from 0 to $100 \mathrm{nM}$ could be analyzed, with high sensitivity and selectivity, with a limit of detection of $2.48 \mathrm{pM}$.
\end{abstract}

Keywords: Salmonella, Molecular diagnostic, Retroreflective Janus particles, Optical biosensor, Stem-loop DNA

\section{Introduction}

Salmonella is one of the most common foodborne pathogens. It can infect both animals and humans and cause various symptoms including fever, diarrhea, nausea, vomiting, and even death [1]. According to recent studies, 93.8 million cases of salmonellosis occur every year, resulting in 155,000 deaths annually [2]. Deaths due to Salmonella infection occur worldwide, regardless of nationality, including in the United States, the United Kingdom, Australia, and Africa [3]. Therefore, the detection of Salmonella is important in the food industry.

\footnotetext{
*Correspondence: hcyoon@ajou.ac.kr

Department of Molecular Science \& Technology, Ajou University, Suwon 16499, Republic of Korea
}

Culture-based methods are considered to be standard for the diagnosis of Salmonella. However, they are not widely used due to their time-consuming nature. Other disadvantages of these methods include costly and complicated equipment and the need for skilled workers. To overcome these limitations, immunoassay-based colorimetric methods have been introduced as alternatives to culture-based methods for the diagnosis of Salmonella [4-7]. Immunoassays based on chromogenic reactions have an advantage that the resulting signals can be quickly and easily detected as a color change. However, these methods require magnetic particles to capture the target pathogen in a pre-enrichment step. To eliminate this pre-enrichment step, direct target-measurement methods have been introduced, including ATP 
bioluminescence [8], strip-based lateral flow immunoassay [9], surface plasmon resonance (SPR)-based enzymatic precipitation enhancement methods [10], and M13 bacteriophage-based SPR detection methods [11]. Although eliminating the pre-enrichment step allowed Salmonella detection in a short time (within $60 \mathrm{~min}$ ), the limit of detection (LOD) of these assays is relatively high $\left(10^{3}-10^{4} \mathrm{CFU} / \mathrm{mL}\right)$.

In recent years, various nucleic acid-based Salmonella diagnostic methods have been developed, including fluorescence-based, colorimetric, and electrochemical methods, to improve the sensitivity of detection [12-15]. In particular, methods using stem-loop DNA as a probe has attracted much attention because of the advantage of being able to clearly detect the on-off signal [16-18]. Stem-loop DNA probes consist of two regions; one is the loop region, which has a sequence that is complementary to the target gene DNA, and the other is the stem region, which has a fluorescent molecule at one end and a quencher at the other end. When the target is absent, the stem-loop DNA probe exists as a hairpin structure, and no fluorescence is detected due to the close proximity of the quencher. When the target is present, the stem-loop DNA probe is stretched due to hybridization of the target gene DNA to the loop region, which separates the quencher from the fluorescent molecule, allowing it to fluoresce. These fluorescence-based Salmonella detection methods have good sensitivity. Although a lot of effort has been dedicated to the development of such methods for the detection of Salmonella, these assays remain challenging because they require a sophisticated instrument.

In this study, we applied a retroreflective Janus microparticle (RJP) to overcome the requirement for complex equipment in fluorescence-based Salmonella diagnosis. An RJP is a non-spectroscopic optical probe that does not require sophisticated equipment for analysis [1921]. Thus, the integration of an RJP in a stem-loop DNA probe-based Salmonella assay will allow highly sensitive detection using a simple optic system. To develop this assay, two DNAs were prepared, the stem-loop DNA probe and target gene DNA. The stem-loop DNA probe, which is modified with biotin, was immobilized on a sensing surface. As shown in the Fig. 1, in the presence of the target gene DNA on the sensing surface, the stemloop DNA probe would be stretched, exposing biotin.

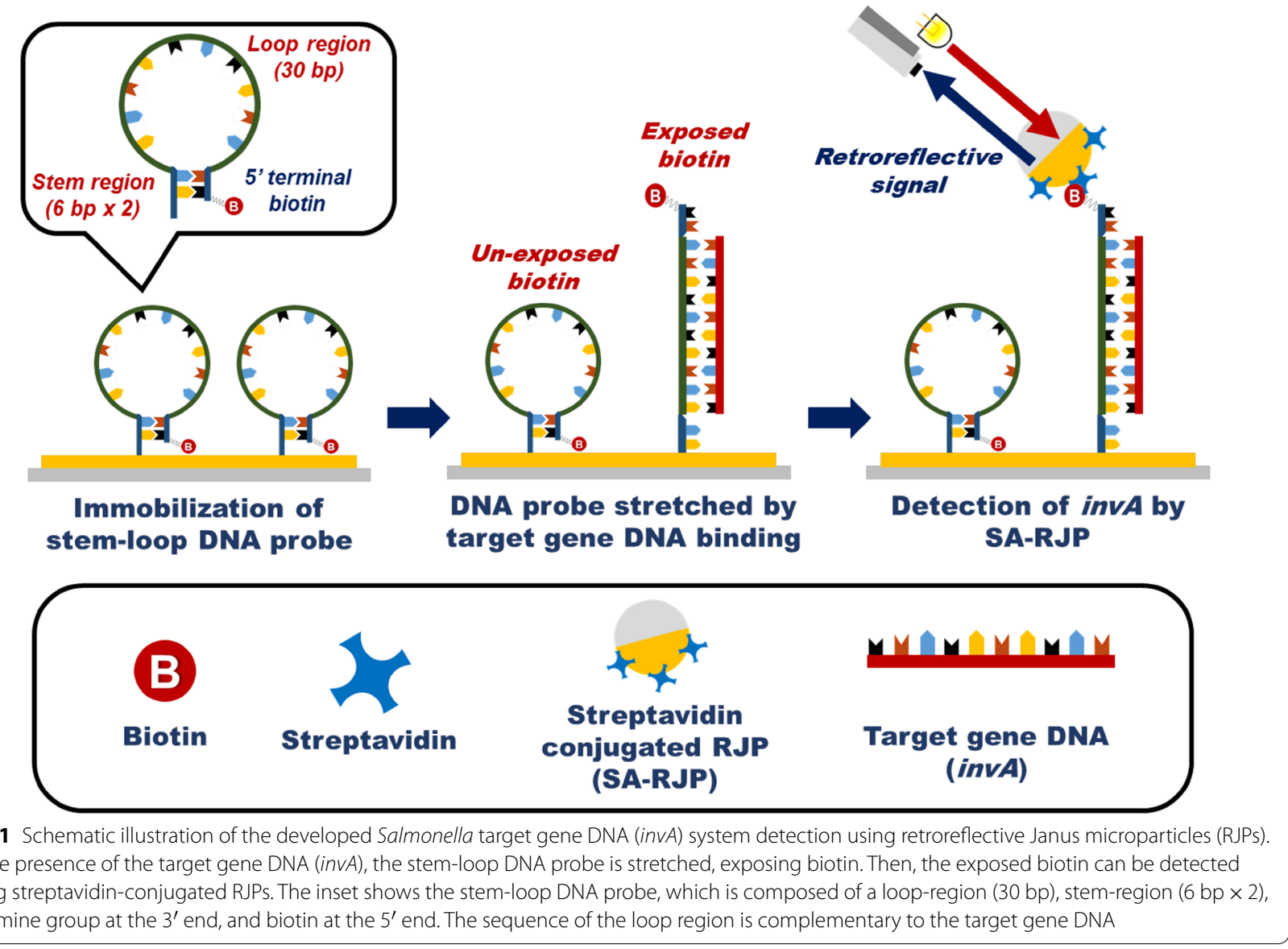


Then, when the streptavidin-conjugated RJP (SA-RJP) is added to the sensing surface, the SA-RJP can react with the exposed biotin. Since the amount of exposed biotin is proportional to the concentration of the target gene DNA, quantitative detection of Salmonella can be accomplished by counting the number of observed SARJPs. Moreover, this sensing strategy has another advantage as the RJPs can be detected using a simple optical system, such as a white LED and commercial complementary metal-oxide semiconductor (CMOS) camera. The details of the developed sensing system and the experimental results are described below.

\section{Experimental}

\subsection{Materials and instruments}

A biotinylated stem-loop DNA probe, a target gene DNA, and mismatched target genes were synthesized by Bioneer (Daejeon, Korea). The retroreflective Janus particle-quantifying chips (RQC) were acquired from AMED (Seoul, Korea). Streptavidin and 3,3'-dithiobis (sulfosuccinimidyl propionate) (DTSSP) were obtained from Thermo Scientific (MA, USA). Ethanolamine (EA), tris(hydroxymethyl)aminomethane, sodium dodecyl sulfate (SDS), sucrose, arginine, Tween-20, Triton X-100, polyethylene glycol (PEG), and poly(vinyl alcohol) (PVA) were purchased from Sigma-Aldrich (MO, USA). Bovine serum albumin (BSA) was obtained from BioWorld $(\mathrm{OH}$, USA). Sodium chloride $(\mathrm{NaCl})$ was obtained from Duchefa Biochemie (Haarlem, Netherlands). The storage buffer was purchased from Ademtech (Pessac, France). All other reagents were analytical grade. The $\mathrm{VZM}^{\mathrm{TM}} 450 \mathrm{i}$ Zoom Imaging Lens and CMOS Color USB Camera (5 megapixels) were purchased from Edmund Optics (NJ, USA). Reaction buffer solution (RBS) consisted of $10 \mathrm{mM}$ Tris$\mathrm{HCl}$ and $200 \mathrm{mM} \mathrm{NaCl}, \mathrm{pH}$ 8.0. Washing buffer solution I (WBS I) consisted of $10 \mathrm{mM}$ Tris- $\mathrm{HCl}, 200 \mathrm{mM} \mathrm{NaCl}$, and $0.1 \%$ SDS, $\mathrm{pH}$ 8.0. Washing buffer II solution (WBS II) consisted of $20 \mathrm{mM}$ Tris- $\mathrm{HCl}, 1 \% \mathrm{BSA}, 1 \%$ sucrose, $50 \mathrm{mM} \mathrm{NaCl}, 50 \mathrm{mM}$ arginine, $0.2 \%$ Tween-20, 0.2\% Triton X-100, 0.2\% PEG, and 0.5\% PVA, pH 7.4. PBST buffer consisted of $0.02 \%$ Triton X-100 in $50 \mathrm{mM}$ phosphatebuffered saline (PBS) solution. All buffer solutions were made with double distilled, deionized water (DDW).

\subsection{Preparation of the sensing surface and streptavidin-conjugated RJP}

To detect Salmonella, a stem-loop DNA was used as a molecular probe, and the sequence is shown in Table 1. The stem-loop DNA probe was immobilized on the RJPquantifying chip (RQC), which was used as a sensing surface. The real images of RQC (in a microfluidic chip, magnified view, and cross-sectional view) were shown in Additional file 1: Figure S1. Briefly describing the RQC,
Table 1 The sequences of the stem-loop DNA probe and the target gene

\begin{tabular}{ll}
\hline & Sequence \\
\hline Stem-loop DNA probe & 5'-Biotin- $\left(\mathrm{CH}_{2}\right)_{6}-$ GTGAGCAAAGAGACCTACCAT \\
Target gene DNA & ACGGGCCATTTGCTGCTCAC- $\left(\mathrm{CH}_{2}\right)_{6}-\mathrm{NH}_{2}-3^{\prime}$ \\
& 3'-TTTCTCTGGATGGTATGCCCGGTAACAGA-5'
\end{tabular}

In the stem-loop DNA probe, the underlined sequence is the sequence that is complementary to the target gene

the RQC contains 16 patterned regions made of gold $\left(340 \times 340 \mu \mathrm{m}^{2}\right)$ and is composed of a $30-\mathrm{nm}$ chromium layer and a $150-\mathrm{nm}$ gold layer on a glass surface, which was generated by using a conventional photolithography technique. The method used to construct the sensing surface was described previously [20]. Briefly, the RQC was cleaned with piranha solution $\left(\mathrm{H}_{2} \mathrm{SO}_{4}: \mathrm{H}_{2} \mathrm{O}_{2} ; 4: 1\right)$ and then rinsed with DDW three times. Next, DTSSP was applied to the RQC and reacted for $3 \mathrm{~h}$ to form the self-assembled monolayer (SAM). Then, the RQC was washed with DDW three times. Next, $20 \mu \mathrm{L}$ of the stemloop DNA probe was applied to DTSSP-treated RQC for $1 \mathrm{~h}$, and the amine group on one end of the stem-loop reacted with the sulfo- $\mathrm{N}$-hydroxysuccinimide (NHS) ester of DTSSP. During this step, the stem-loop DNA probe was covalently immobilized on the gold surface via an amide bond. To prevent self-hybridization of the stem-loop DNA probes, the reaction temperature was increased to $40{ }^{\circ} \mathrm{C}$. Then, the un-immobilized stem-loop DNA probes were washed away with WBS I $(700 \mu \mathrm{L})$, and the unreacted NHS moieties of DTSSP were blocked with $20 \mathrm{mM}$ ethanolamine for $30 \mathrm{~min}$.

Next, the modification of the RJP surface was conducted. The RJP with a diameter of $\sim 1.2 \mu \mathrm{m}$ was synthesized according to the previously reported method [19]. The prepared-RJPs were conjugated to streptavidin, which specifically binds to biotin [20]. In brief, DTSSP $(5 \mathrm{mM})$ was immobilized on the gold region of the RJPs by using the SAM technique for $3 \mathrm{~h}$. After washing away the unreacted DTSSP, streptavidin was conjugated in the same manner used to construct the sensing surface. To block the unreacted region of the RJPs, they were treated with $20 \mathrm{mM}$ ethanolamine for $30 \mathrm{~min}$ and with $1 \%$ BSA solution for $1 \mathrm{~h}$. Then, the particles were sonicated in the buffer and stored in Ademtech storage buffer until use.

\subsection{Optimization of the stem-loop DNA probe concentration}

The concentration of the immobilized stem-loop DNA probe was optimized to achieve a high signal-to-noise ratio. For this experiment, various concentrations of the stem-loop DNA probe, ranging from 10 to $50 \mu \mathrm{M}$, were immobilized on the RQC. After blocking unreacted 
DTSSP with $20 \mathrm{mM}$ ethanolamine, $20 \mu \mathrm{L}$ of the target gene DNA $(1 \mu \mathrm{M})$ diluted in RBS was applied to the sensing surface where various concentrations of the stem-loop DNA probe were immobilized. To confirm the background signal, $20 \mu \mathrm{L}$ of RBS containing no target gene DNA was used as a negative control. The measurement procedure was the same as that described in the calibration study in Sect. 2.4.

\subsection{Measurement of target gene DNA detected using RJPs}

For assessing the molecular diagnosis of Salmonella using the developed method, the target gene DNA was injected into the RQC that was modified with the stem-loop DNA probe. The RQC was incubated with the target gene DNA for $45 \mathrm{~min}$ at $40^{\circ} \mathrm{C}$, a temperature that is sufficient to allow the stem-loop DNA probe to stretch and expose the biotin. Then, the temperature was reduced to $4{ }^{\circ} \mathrm{C}$ for $15 \mathrm{~min}$ to promote the formation of the hairpin structure in the stemloop DNA probes that were not hybridized to the target gene DNA. The unhybridized and non-specifically bound target gene DNAs were washed away with WBS I $(700 \mu \mathrm{L})$. Then, to minimize non-specific binding between RJPs and the RQC, the sensing surface was blocked with $1 \%$ BSA. After blocking for $1 \mathrm{~h}$, the sensing surface was washed with PBST $(600 \mu \mathrm{L})$. To detect the exposed biotin, SA-RJPs $(0.4 \mathrm{mg} / \mathrm{mL})$ were injected into the sensing surface. After $15 \mathrm{~min}$, the unreacted RJPs were washed away with WBS II $(700 \mu \mathrm{L})$. The RJPs reacted with the biotin were observed with a CMOS camera under a white LED light, and an image of the RJPs was obtained. Then, the number of RJPs in the obtained images was analyzed by counting with NIH Image J.

\subsection{Selectivity test with mismatched target genes}

To verify the target gene DNA selectivity of the developed RJP-based molecular diagnostic system, singlestranded DNAs with different sequences from that of the target gene DNA were prepared. Mismatched gene 1 (M1), mismatched gene 2 (M2), and mismatched gene 3 (M3) had one, two, and three nucleotide differences, respectively, compared to the target gene DNA sequence. The sequences of the mismatched genes are shown in Table 2. A $20 \mu \mathrm{L}$ aliquot of each $100 \mathrm{nM}$ mismatched gene diluted in RBS buffer was injected into the prepared sensing surface. For comparison, the same concentration of the target gene DNA and RBS were included as positive and negative controls, respectively. Sample detection was performed as described in Sect. 2.4.

\section{Results and discussion}

\subsection{Principle of Salmonella detection using a retroreflective biosensing platform}

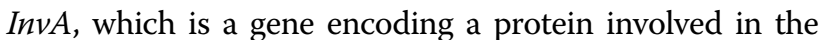
invasion of Salmonella through a type 3 secretion system,
Table 2 The sequences of the mismatched genes

\begin{tabular}{|c|c|}
\hline & Sequence \\
\hline Mismatched gene 1 (M1) & $3^{\prime}$-TTTCTCTGGATGGTATCCCCGGTAAACAGA-5' \\
\hline Mismatched gene 2 (M2) & 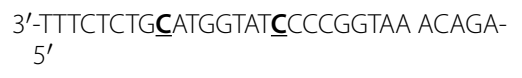 \\
\hline Mismatched gene 3 (M3) & $3^{\prime}$-TTTCTCTG스GGGTATㄷCCCGGTAIACAGA-5' \\
\hline
\end{tabular}

The mismatched bases are shown as bold letters and underlined

has been widely used as a target gene DNA for the diagnosis of Salmonella [22-24]. Therefore, to analyze Salmonella with the retroreflective optical detection system developed by us, the invA that is conserved in diverse Salmonella serotypes was selected as the target gene DNA (427 bp to $456 \mathrm{bp}$ of CDS) $[25,26]$. In this study, to detect Salmonella, we designed and prepared a stem-loop DNA probe that can hybridize to invA. The stem-loop DNA probe, which is capable of specific binding to the target gene DNA, consisted of 42 base pairs. The stem-loop DNA probe has two regions, the loop and stem regions, as well as a biotin residue at the $5^{\prime}$ end and an amine group at the $3^{\prime}$ end with six carbon linkers. The sequences of the stem-loop DNA probe and target gene DNA are shown in Table 1.

The loop region ( $30 \mathrm{bp}$ ) contains the specific sequence that is complementary to $i n v A$. In addition, the stem region $(6 \mathrm{bp} \times 2)$, which is present at the $3^{\prime}$ and $5^{\prime}$ ends of the stem-loop DNA probe is capable of forming a double-stranded stem structure. Therefore, in the absence of the target gene DNA, the stem-loop DNA probe exists as a hairpin structure that is formed by hybridization of the two complementary stem regions. The closed form of the stem-loop DNA probe cannot bind to the SA-RJPs because the biotin present at the $5^{\prime}$ end is shielded by steric hindrance [27]. In contrast, in the presence of the target gene DNA, the stem-loop DNA probe is stretched due to hybridization between the target gene DNA and loop region of the stem-loop DNA probe, which exposes biotin. Since the amount of exposed biotin in the stretched stem-loop DNA probe increases in proportion to the increase in target gene DNA concentration, the number of RJPs that can bind to biotin increases proportionally. Therefore, the target gene DNA could be quantitatively analyzed by counting the number of observed RJPs. In addition, because the RJPs can be measured using simple optical equipment, such as a CMOS camera and a white LED, the developed biosensing system has the advantage of being able to detect Salmonella without a sophisticated optical instrument.

\subsection{Optimization of the concentration of immobilized stem-loop DNA probe}

To effectively detect the target gene DNA, a high signal in the presence of the target gene DNA and a low 
background signal are required. To achieve this high signal-to-noise ratio, the concentration of the immobilized stem-loop DNA probe should be optimized. Prior to determining the optimal concentration of the stemloop DNA probe, since the RJP and RQC were used as an optical probe and sensing surface, respectively, it was necessary to confirm that the DNA and streptavidin were immobilized on the RQC and RJP. In a previous study, we confirmed the streptavidin modification on the RJP surface and that the stem-loop DNA probe was immobilized on the RQC [20]. Therefore, we assumed that the RJP and RQC could be used in this study as an optical probe and sensing surface, respectively, without verification. To determine the optimal concentration of the stemloop DNA probe, various concentrations of the probe $(10-50 \mu \mathrm{M})$ were applied to the RQC, and the number of observed RJPs was measured (Fig. 2).

As shown in Fig. 2, in the absence of the target gene DNA, the numbers of observed RJPs were similar regardless of the concentration of the stem-loop DNA probe immobilized on the sensing surface, because the biotin was not exposed. These values were considered to be the background signal, indicating that the developed biosensing surface has a constant background signal.

In contrast, in the presence of $1 \mu \mathrm{M}$ target gene DNA, the number of observed RJPs increased in proportion to the concentration of the immobilized stem-loop DNA probe. As shown in Fig. 2, 162.7 RJPs were observed when the stem-loop DNA probe concentration was $40 \mu \mathrm{M}$. Similarly, about 176.0 RJPs were observed in the presence of $50 \mu \mathrm{M}$ stem-loop DNA probe. However, the background signal at the $50 \mu \mathrm{M}$ stem-loop DNA probe

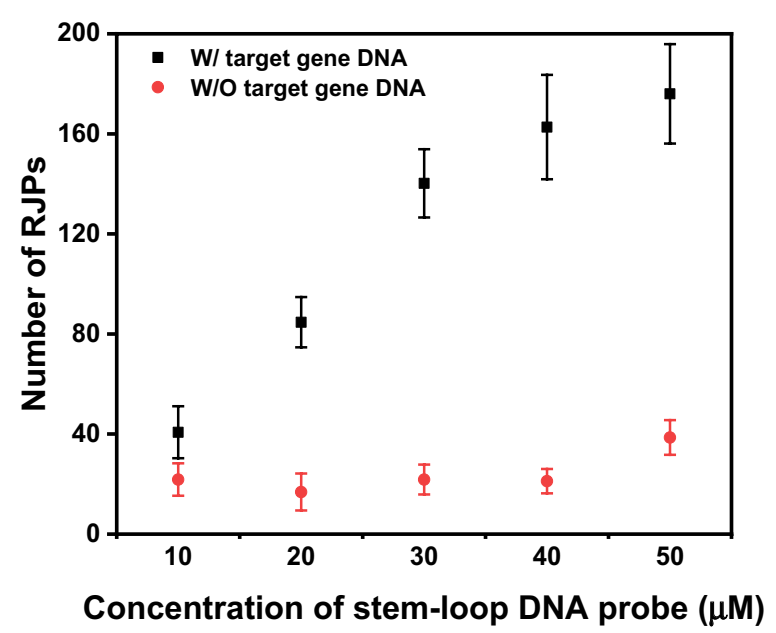

Fig. 2 Optimization of the concentration of the stem-loop DNA probe immobilized on the sensing surface. Various concentrations of the stem-loop DNA probe were immobilized to determine the optimal concentration concentration was 38.6 RJPs, which is relatively higher than the signal observed at $40 \mu \mathrm{M}(21.2 \mathrm{RJPs})$. Although the observed signal was the highest at $50 \mu \mathrm{M}$ stem-loop DNA probe, it was not significantly higher than the signal at $40 \mu \mathrm{M}$. Furthermore, a low background signal was measured at $40 \mu \mathrm{M}$. These results indicate that $40 \mu \mathrm{M}$ was sufficient to detect the target gene DNA with a high signal-to-noise ratio. Therefore, the optimal stem-loop DNA probe concentration was $40 \mu \mathrm{M}$.

\subsection{Calibration study for the developed retroreflective biosensing platform using a stem-loop DNA probe and RJPs}

To confirm that the developed stem-loop DNA-based molecular biosensing system is capable of detecting Salmonella, a diagnostic test was performed. Since the purpose of this study was to determine if quantitative analysis of Salmonella is possible, we prepared and analyzed various concentrations of the target gene DNA (0.01-100 nM). Each target gene DNA solution was injected onto an RQC with immobilized stem-loop DNA probe (at $40 \mu \mathrm{M}$ ), and the RQCs were incubated at a temperature above the $T_{m}$ of the stem structure in the stemloop DNA probe. During incubation, the stem-loop DNA probes are unfolded, allowing hybridization between the loop region and the target gene DNA, and thus exposing the biotin at $5^{\prime}$-terminal. Then, to refold the hairpin structure of stem-loop DNA probes that did not bind to the target gene DNA, the RQCs were incubated at the temperature of $4{ }^{\circ} \mathrm{C}$ for $15 \mathrm{~min}$. Then, the SA-RJPs were injected onto the RQCs. As described in principle section, the SA-RJPs could react with the biotin present at the end of a stretched-stem-loop DNA probe. Since the number of reacted RJPs is positively correlated with the concentration of the target gene DNA, quantitative analysis of the target gene DNA could be achieved by counting the number of observed RJPs.

Figure 3a shows an image of results acquired with the CMOS camera. The number of RJPs in the image increased as the concentration of target gene DNA increased. For the quantitative analysis, NIH Image J was used to count the number of RJPs in the image. The number of counted RJPs is shown in Fig. 3b. When the target gene DNA concentration was $0 \mathrm{nM}, \sim 19.6$ RJPs were detected. This value could be regarded as the background signal due to non-specific binding of the SA-RJPs to the RQC and because the target gene DNA is not present. To verify the reproducibility of the background signal, the same experiment was carried out at least five times, and the standard deviation of the mean was $\sim 10 \%$. The background signal in the calibration study was similar to the background signal shown in Sect. 3.2, indicating that the obtained background signal is reliable. When 

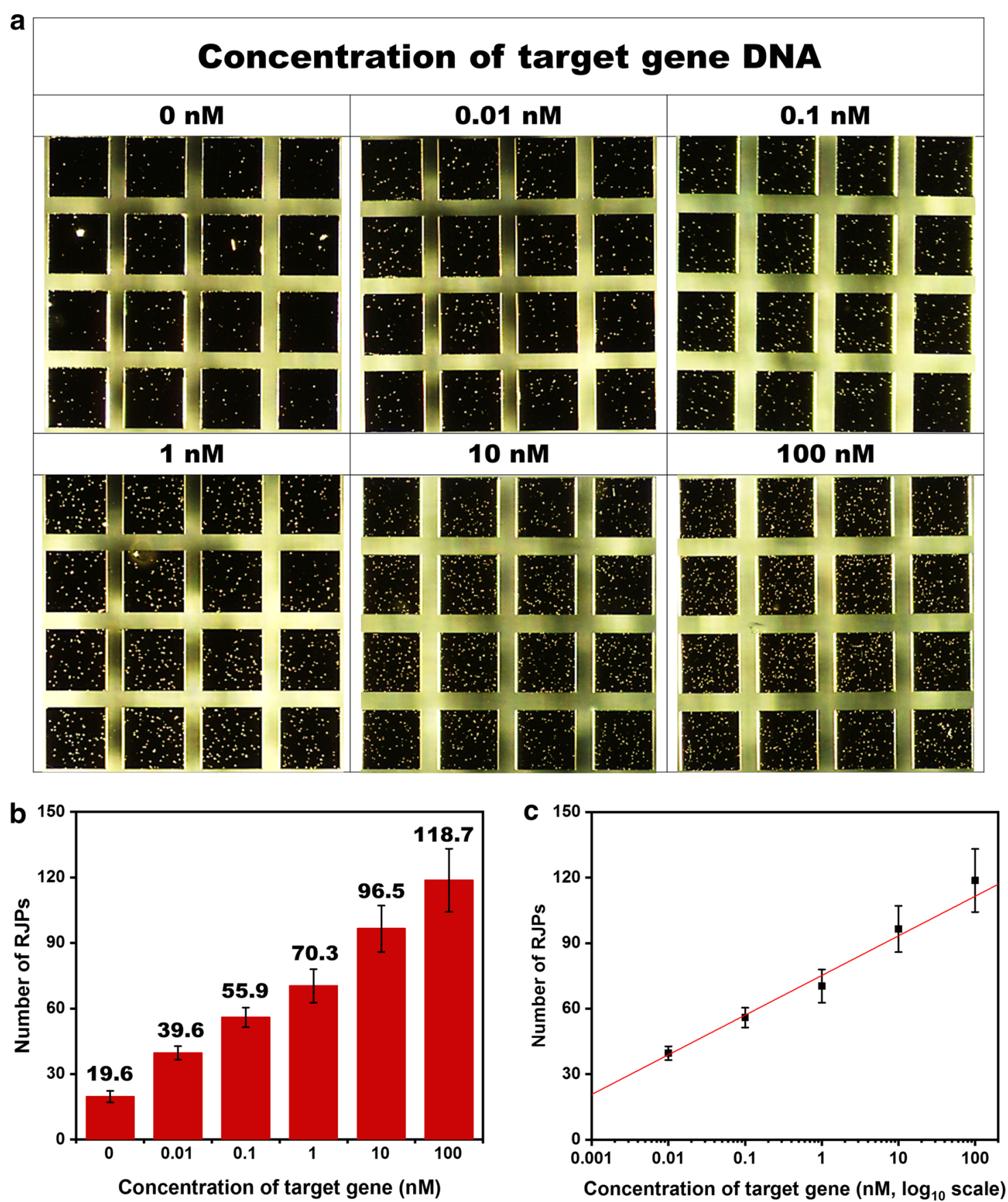

Fig. 3 a Images of the RJPs on the RQC in a Salmonella detection assay with various invA concentrations $(0,0.01,0.1,1,10$, and $100 \mathrm{nM})$ performed using the developed optical sensing platform. $\mathbf{b}$ The graph shows the number of bound RJPs, which was calculated from images using Image J. $\mathbf{c}$ The calibration curve for the invA assay on a log scale. Linear regression analysis was performed, and the error bars are the standard deviation

the concentration of the target gene DNA was $100 \mathrm{nM}$, 118.7 RJPs were detected. As the concentration of the target gene DNA increased, the number of observed RJPs increased by 20 RJPs for each tenfold increase from 0.01 to $100 \mathrm{nM}$. Figure $3 \mathrm{c}$ shows a linear calibration graph that was obtained from experiments using 0-100 $\mathrm{nM}$ target gene DNA. Using the acquired calibration curve, the limit of blank (LOB) and limit of detection (LOD) of the developed biosensing system were calculated as $1.47 \mathrm{pM}$ and $2.84 \mathrm{pM}$, respectively. A number of studies have been 
conducted regarding the Salmonella detection by using fluorescence-based detection. Reported LOD values from these papers were around $1 \mathrm{nM}$ or 2 CFU (colony forming unit), showing the competitiveness of current approach $[16,28,29]$. In addition, while the fluorescencebased sensing requires sophisticated optical activation/ detection setup, the retroreflective non-spectroscopic sensing could be conducted with the simple optical system.

\subsection{Verification of the selectivity of the developed molecular diagnosis system}

To be a useful biosensor capable of detecting and measuring Salmonella contamination, the RJP-based optical signals obtained with the developed biosensing system should originate from DNA-DNA interaction between the stem-loop DNA probe and the target gene DNA. In other words, the stem-loop DNA probe should be unfolded only in the presence of the target gene DNA. Therefore, to confirm that the stem-loop DNA probe is not unfolded by the presence of other genes with similar sequences, a selectivity test was performed. For the selectivity test, single-strand DNAs that differ from the target gene DNA by several nucleotides were prepared (Table 2).

These genes were named mismatched gene 1 (M1), mismatched gene 2 (M2), and mismatched gene 3 (M3) depending on the number of different nucleotides (the bold red underlined bases in Table 2 are different from the target gene DNA). When these mismatched genes were injected onto the stem-loop DNA probe-immobilized RQC, the mismatched genes did not perfectly hybridize to the stem-loop DNA probe, and the stemloop DNA probe did not stretch, unlike when the target gene DNA, which has a complementary sequence, was hybridized to the stem-loop DNA probe. Therefore, the number of detected RJPs was fewer than when the complementary target gene DNA was used, because fewer biotin molecules are exposed than in the presence of the target gene DNA.

Figure 4 shows the number of observed RJPs when these mismatched genes (diluted in RBS to $100 \mathrm{nM}$ ) were injected onto the developed biosensing system. For a more accurate comparison with the results obtained using the target gene DNA, the change in the number of RJPs was used, which was obtained by subtracting the background signal from the number of observed particles. For M1, the change in the number of observed RJPs was 35.9 , which was $35.6 \%$ of the number of RJPs detected with the target gene DNA. Similarly, when M2 and M3 were tested with the developed biosensing system, the change in the number of

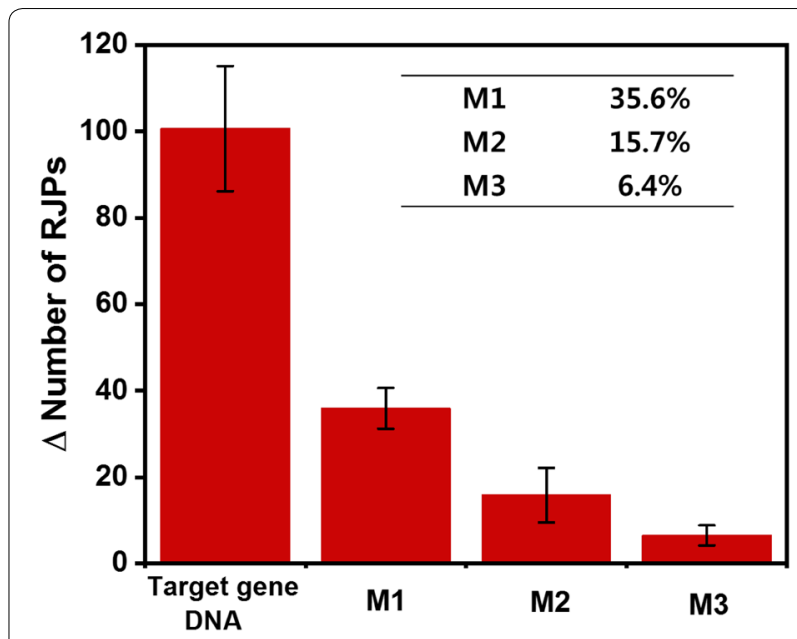

Fig. 4 Results of the selectivity test. The change $(\Delta)$ in the number of RJPs detected was calculated by subtracting the background from the number of RJPs detected. The target gene DNA, mismatched gene 1 (M1), mismatched gene 2 (M2), and mismatched gene 3 (M3) were used at a concentration of $100 \mathrm{nM}$. The inset shows the ratio of RJPs for the mismatched genes compared to the target gene DNA, which was set to $100 \%$

observed RJPs was 15.8 and 6.4, which was calculated to be $15.7 \%$ and $6.4 \%$ of that for the target gene DNA, respectively. In previous studies, when one mismatched nucleotide was present in a sequence, $\sim 30 \%$ of the signal obtained with the complementary target gene DNA was detected [30-32]. Since the results obtained from the developed biosensing system show the same tendency as that reported previously, the selectivity of the developed biosensing system is believed to be reliable. Taken together, these results show that the developed biosensing system has excellent selective detection capability for Salmonella.

\section{Conclusions}

In this study, we developed a Salmonella sensing platform using RJPs with a simple optical system. The developed sensing platform using RJPs does not require sophisticated optical equipment, compared with conventional fluorescence-based detection systems for Salmonella, because the RJPs can be observed using a common white LED and a CMOS camera. Using this sensing system, highly sensitive, quantitative analysis of Salmonella was successfully achieved. In addition, we confirmed that the developed system has high selectivity for $i n v A$ using oligonucleotides with mismatched sequences. Based on the results of this research, we believe that the developed sensing system is an attractive platform for the detection of food-borne pathogens such as Salmonella. 


\section{Additional file}

Additional file 1: Figure S1. (A) The image of RQC (RJP-quantifying chip); (B) The magnified view of the sensing surface of RQC; (C) Schematic illustration of the cross-section of RQC.

\section{Abbreviations}

RJP: retroreflective Janus microparticle; SA-RJP: streptavidin-conjugated RJP; SPR: surface plasmon resonance; LOD: limit of detection; CFU: colony forming unit; CMOS: commercial complementary metal-oxide semiconductor; LED: light emitting diode; RQC: retroreflective Janus particle-quantifying chips; DTSSP: 3,3'-dithiobis (sulfosuccinimidyl propionate); SAM: self-assembled monolayer; WBS: washing buffer solution; RBS: reaction buffer solution; NHS: sulfo-N-hydroxysuccinimide; EA: ethanolamine; SDS: sodium dodecyl sulfate; PEG: polyethylene glycol; PVA: poly(vinyl alcohol); BSA: bovine serum albumin; $\mathrm{NaCl}$ : sodium chloride; DNA: deoxyribonucleic acid; PBS: phosphate buffer saline; PDMS: polydimethylsiloxane.

\section{Authors' contributions}

DWK, HJC and HCY designed this work and wrote the manuscript. HJC and JHK synthesized and characterized RJPs. DWK and HY prepared samples and conducted pathogen assay. All authors read and approved the final manuscript.

\section{Acknowledgements}

This research was supported by the Samsung Research Funding Center of Samsung Electronics (Project Number SRFC-IT1401-51) and the National Research Foundation of Korea (NRF-2018R1D1A1A02085354).

\section{Competing interests}

The authors declare that they have no competing interests.

\section{Availability of data and materials}

The datasets used and/or analysed during the current study are available from the corresponding author on reasonable request.

\section{Funding}

Samsung Research Funding Center of Samsung Electronics (Project Number SRFC-IT1401-51) for HCY and the National Research Foundation of Korea (NRF2018R1D1A1A02085354) for HCY.

\section{Publisher's Note}

Springer Nature remains neutral with regard to jurisdictional claims in published maps and institutional affiliations.

Received: 30 March 2019 Accepted: 26 April 2019

Published online: 15 May 2019
References

1. J.R. Kurtz, J.A. Goggins, J.B. McLachlan, Immunol. Lett. 190, 42 (2017)

2. S. Kim, E. Kim, S. Park, T.W. Hahn, H. Yoon, Microbiol. Biotechnol. 27, 1983 (2017)

3. E. Scallan, R.M. Hoekstra, F.J. Angulo, R.V. Tauxe, M.A. Widdowson, S.L. Roy, J.L. Jones, P.M. Griffin, Emerg. Infect. Dis. 17, 7 (2011)

4. M. Srisa-Art, K.E. Boehle, B.J. Geiss, C.S. Henry, Anal. Chem. 90, 1035 (2018)

5. M.M.A. Zeinhom, Y. Wang, L. Sheng, D. Du, L. Li, M.J. Zhu, Y. Lin, Sens. Actuators B Chem. 261, 75 (2018)

6. Q. Sun, G. Zhao, W. Dou, Sens. Actuators B Chem. 226, 69 (2016)

7. H.J. Kim, S.J. Choi, Biochip J. 12, 52 (2018)

8. J. Lee, C. Park, Y. Kim, S. Park, Biochip J. 11, 287 (2017)

9. S. Park, Y.T. Kim, Y.-K. Kim, Biochip J. 4, 110 (2010)

10. Z. Farka, T. Juř́k, M. Pastucha, P. Skládal, Anal. Chem. 88, 11830 (2016)

11. I. Kim, J.-S. Moon, J.-W. Oh, Nano Converg. 3, 27 (2016)

12. Z. Wang, H. Xu, J. Wu, J. Ye, Z. Yang, Food Chem. 125, 779 (2011)

13. Z. Fu, X. Zhou, D. Xing, Sens. Actuators B Chem. 182, 633 (2013)

14. A. Singh, G. Sinsinbar, M. Choudhary, V. Kumar, R. Pasricha, H.N. Verma, S.P. Singh, K. Arora, Sens. Actuators B Chem. 185, 675 (2013)

15. Y. Ye, Y. Liu, S. He, X. Xu, X. Cao, Y. Ye, H. Zheng, Sens. Actuators B Chem. 272, 53 (2018)

16. N.C. Cady, A.D. Strickland, C.A. Batt, Mol. Cell. Probes 21, 116 (2007)

17. K.P. Burris, T.-C. Wu, M. Vasudev, M.A. Stroscio, R.J. Millwood, C.N. Stewart, I.E.E.E. Trans, Nanobioscience. 12, 233 (2013)

18. O. Adegoke, E.Y. Park, Nano Converg. 3, 32 (2016)

19. Y.D. Han, H.S. Kim, Y.M. Park, H.J. Chun, J.H. Kim, H.C. Yoon, A.C.S. Appl, Mater. Interfaces 8, 10767 (2016)

20. H.J. Chun, S. Kim, Y.D. Han, D.W. Kim, K.R. Kim, H.S. Kim, J.H. Kim, H.C. Yoon, Biosens. Bioelectron. 104, 138 (2018)

21. H.J. Chun, S. Kim, Y.D. Han, K.R. Kim, J.H. Kim, H. Yoon, H.C. Yoon, ACS Sens. 3, 2261 (2018)

22. Q. Li, W. Cheng, D. Zhang, T. Yu, Y. Yin, H. Ju, S. Ding, Int. J. Electrochem. Sci. 7, 844 (2012)

23. K. Rahn, S.A. De Grandis, R.C. Clarke, S.A. McEwen, J.E. Galan, C. Ginocchio, R. Curtiss III, C.L. Gyles, Mol. Cell. Probes. 6, 271 (1992)

24. E.-S. Jeong, K.-S. Lee, S.-H. Heo, J.-H. Seo, Y.-K. Choi, Exp. Anim. 60, 65 (2011)

25. L.T. Daum, W.J. Barnes, J.C. Mcavin, M.S. Neidert, L.A. Cooper, W.B. Huff, W.S. Riggins, S. Morris, A. Salmen, L. Lohman, L. Gaul, K.L. Lohman, J. Clin. Microbiol. 40, 3050 (2002)

26. J.E. Galan, C. Ginocchio, P. Costeas, J. Bacteriol. 174, 4338 (1992)

27. X. Fang, W. Jiang, X. Han, Y. Zhang, Microchim. Acta 180, 1271 (2013)

28. H. Liu, W. Shu, Z. Liu, B. Zhang, H. Feng, Y. Chen, Microfluid. Nanofluid. 21, 67 (2017)

29. W. Chen, G. Martinez, A. Mulchandani, Anal. Biochem. 280, 166 (2000)

30. Q. Guo, Z. Bai, Y. Liu, Q. Sun, Biosens. Bioelectron. 77, 107 (2016)

31. Y. Jin, X. Yao, Q. Liu, J. Li, Biosens. Bioelectron. 22, 1126 (2007)

32. Q. Hu, X. Deng, J. Kong, Y. Dong, Q. Liu, X. Zhang, Analyst 140, 4154 (2015)

\section{Submit your manuscript to a SpringerOpen ${ }^{\circ}$ journal and benefit from:}

- Convenient online submission

- Rigorous peer review

- Open access: articles freely available online

- High visibility within the field

- Retaining the copyright to your article

Submit your next manuscript at springeropen.com 